\title{
A IMPORTÂNCIA DA RESERVA LEGAL NA GERAÇÃO DE RENDA DOS PEQUENOS PRODUTORES RURAIS: ESTUDO DE CASO NO ESTADO DO ACRE, AMAZÔNIA
}

\author{
Ronei Sant'Ana de Menezes*, Anadalvo Juazeiro dos Santos ${ }^{* *}$, Ricardo Berger ${ }^{\star *}$ \\ * Eng. Agrônomo, M.Sc., Curso de Pós-Graduação em Engenharia Florestal, UFPR \\ ** Eng. Florestal, Dr., Depto. de Economia Rural e Extensão, UFPR - ajsantos@floresta.ufpr.br - berger@bsi.com.br \\ Recebido para publicação: 13/09/2004 - Aceito para publicação: 14/02/2005
}

\begin{abstract}
Resumo
A importância da reserva legal na geração de renda dos pequenos produtores rurais: estudo de caso no estado do Acre, Amazônia. Este trabalho teve como principal objetivo contribuir na formulação de políticas regionais voltadas ao desenvolvimento econômico rural sustentável. Analisa a viabilidade econômica de pequenas unidades de produção, sob diferentes percentuais de reserva legal em um projeto de assentamento no Estado do Acre. Esta análise considerou o potencial de geração de renda da floresta, utilizando a experiência no Projeto de Assentamento Dirigido Pedro Peixoto, que consta do manejo florestal sustentável para o fornecimento de produtos madeireiros e não-madeireiros de maior relevância, e a geração da renda das famílias considerando quatro cenários de cobertura florestal, sendo a pecuária a atividade predominante na área passiva de conversão. A partir da análise empresarial o estudo identificou como resultados que, comparado à pecuária, o uso múltiplo da floresta apresenta baixa capacidade em gerar receitas para as famílias. Haveria necessidade de investimentos da sociedade direcionados a garantir a manutenção das famílias nas áreas rurais para que estas não arcassem sozinhas com os custos de conservação do ecossistema florestal. A metodologia utilizada poderia ser replicada nas outras unidades de assentamentos que estão em curso no Acre e na Amazônia como um todo.

Palavras-chave: viabilidade econômica; recursos naturais; produtos florestais não-madeireiros; uso da terra; desenvolvimento sustentável; pecuária.
\end{abstract}

\begin{abstract}
The importance of legal reserve on the genarate of revenue from farmers: one case study in the Acre state, Amazon. This study has as the main objective to contribute for the formulation of regional polices forward to the sustainable economics rural development. For that, this study analyzed the economic viability of small production units under unequal percentage of forest cover in a settlement project in the state of Acre. This analysis considerate the potential forest generation, using experience from the Colonization Project Pedro Peixoto which consist of sustainable forest management for supply of timber and more relevant non-timber products, and the farmers revenue generation taking into account four cenarious of forest cover, as well as the cattle ranch as the predominant activity in the subjected to the forest conversion. From private analysis, the study showed results that, compared with the cattle, the multiple use of forest presented a lower capacity of generating revenue for farmers. Should be necessary investments from society for guaranteeing maintenance of rural families, for they for thenselve do not account for cost of ecosystem forest conservation. The methodology used on this study proved that it is possible to be replied in other settlement units in course in the Acre State and all Amazon.

Keywords: economic viability; natural resources; forest non-timber products; land use; sustainable development; cattle.
\end{abstract}

\section{INTRODUÇÃO}

O desmatamento na Amazônia tem sido um dos mais debatidos assuntos ambientais das últimas décadas. As análises das causas de extinção desta vegetação apontam uma ligação entre desmatamento e desenvolvimento da agricultura, considerando também que usos improdutivos e insustentáveis da floresta 
para agricultura e, especificamente para pecuária bovina como os principais responsáveis para a redução da floresta. Neste contexto encontra-se o estado do Acre. Durante décadas a economia deste estado esteve baseada no extrativismo de borracha, castanha e madeira e nos últimos anos vem experimentando profundas mudanças nesta aptidão.

Todo o contexto de desenvolvimento na Amazônia passou por fortes e acirrados debates a partir de 1996, quando o governo federal publicou a Medida Provisória $n^{\circ} 2.166 / 01$, que dentre outros artigos do Código Florestal Brasileiro, mudou de 50 para $80 \%$ os limites de reserva legal das propriedades privadas.

Da mesma forma que em outros estados, no Acre as grandes pressões por parte daqueles que defendem o avanço das fronteiras agrícolas, convertendo áreas de florestas em pastagens para criação de gado fizeram com que técnicos e pesquisadores se debruçassem em justificativas concretas que pudessem sustentar ou alterar este percentual. O governo do estado e a sociedade civil têm como objetivo desenvolver a produção florestal, representada pelos produtos madeireiros e não-madeireiros, estabelecendo medidas de acesso a crédito, assistência técnica e desenvolvimento de cadeias produtivas.

\section{OBJETIVOS}

O presente trabalho aborda a viabilidade econômica de pequenas unidades de produção sob diferentes percentuais de reserva legal em um projeto de assentamento no estado do Acre.

Mais especificamente procurou:

- Avaliar os fluxos anuais de renda familiar em unidades de produção sob tradicionais usos da terra;

- Identificar os níveis de investimentos para assentar e manter as famílias nas unidades de produção em função dos diferentes percentuais de reserva florestal;

- Contribuir na formulação de políticas públicas regionais para o desenvolvimento econômico rural sustentável.

\section{REVISÃO DE LITERATURA}

A Amazônia abrange uma área de aproximadamente 4,5 milhões de quilômetros quadrados, e é considerada a maior floresta tropical contínua atualmente existente no planeta, sendo que a maior parte dessa extensão situa-se em território brasileiro. Ao longo dos últimos quatro anos o Acre, assim como os demais estados da Região, vem experimentando várias práticas na busca do uso racional de seus recursos naturais, tentando reverter um longo período de estagnação econômica e profundas alterações no ecossistema florestal e social, e ao mesmo tempo melhorar os atuais índices de desenvolvimento humano (Acre, 2000).

Apesar de possuir apenas $11 \%$ de seu território antropizado (Inpe, 2004), convive com atividades de uso da terra aliadas ao processo de conversão de florestas em empreendimentos agropecuários que continuam ganhando força e proporcionando grande preocupação aqueles que defendem a conservação dos recursos naturais e a equidade social.

Tradicionalmente as áreas destinadas ao plantio de culturas seguem a mesma dinâmica de processo de conversão anual para pastagem até atingir o limite destinado à criação de bovinos, na primeira fase. Este sistema é conhecido na Amazônia como agricultura do corte-e-queima. Os produtores normalmente necessitam de novas áreas de florestas para produção de arroz, feijão, milho e mandioca porque é desta maneira que buscam fertilidade suficiente para o cultivo, já que não dispõem de fertilizantes, conforme Acre (2000).

A pecuária bovina é o setor da produção primária que mais cresceu nas últimas três décadas. Inserida com o apoio do estado durante a década de 70, praticada principalmente por grandes empresários, a pecuária é a atividade que possui a cadeia produtiva mais consolidada, quando comparada aqueles produtos na forma de grãos e aos do extrativismo. Quanto ao extrativismo, historicamente os três produtos mais importantes são borracha, castanha e madeira. No início do século XX o estado era o maior produtor mundial de borracha, mas o aumento da produção dos seringais de cultivo na Ásia e a produção sintética fizeram com que os seringais nativos da Amazônia perdessem a capacidade competitiva nos mercados nacional e internacional (Rêgo, 2002). 
Conhecendo a exuberância destes produtos no Acre, bem como a importância social, econômica e ambiental dos mesmos, o governo local empenhou-se em executar o Programa de Desenvolvimento do Extrativismo com o subsídio para a produção da borracha, além do estudo das cadeias produtivas da castanha (Bertollettia exelsa) e de outros produtos florestais não-madeiráveis (Acre, 2000).

\section{Uso dos Recursos Naturais}

Desde a aprovação da Medida Provisória $n^{0}$ 2.166/01, que altera a Lei 4.771/65, principalmente na elevação de $50 \%$ para $80 \%$ as áreas a serem mantidas sob reserva legal nas propriedades privadas (Brasil, 2004), os representantes da classe ruralista, representados no país pela Confederação Nacional da Agricultura (CNA) e no estado do Acre pela Federação Nacional da Agricultura, vêm afirmando que tal medida é prejudicial para a Amazônia. Para a classe, a rigidez da medida provisória, que já perdura por oito anos, estaria engessando as perspectivas de crescimento do setor pecuário na região e impedindo quaisquer chances do fortalecimento da agricultura nas pequenas propriedades e nas áreas degradadas, assunto amplamente debatido pelo Jornal O Estado (2003).

A preocupação da sustentabilidade passou a enfocar os assentamentos humanos que vêm sendo implementados pelo Incra na Amazônia. Assim, desde 1999, no extremo oeste do estado do Acre vem sendo realizada uma experiência de nova metodologia de assentamentos em parceria com entidades governamentais e não-governamentais, que tem como objetivo atender os requisitos do desenvolvimento sustentável (Pesacre, no prelo).

\section{Estudos de Viabilidade Econômica e Financeira da Reserva Legal}

Obedecendo as exigências da legislação ambiental pode-se analisar a geração de renda no longo prazo em pequenas propriedades através de instrumentos de análise financeira de empreendimentos rurais. Tal análise, segundo Berger (1980), deve considerar as receitas e custos gerados com a alocação da mão-de-obra, da terra e dos insumos em atividades produtivas diversificadas, como é comum na produção familiar brasileira. De acordo com Dalbello (1998), um resultado positivo nos fluxos de caixa formados significa que esta junção de recursos é remunerada. Tal situação justificaria o incentivo das atividades de manejo florestal e agropecuária com os percentuais que atualmente vigoram.

O resultado negativo indica prejuízos em converter apenas $20 \%$ de reserva legal mesmo considerando um potencial florestal diversificado. Esta seria o que Contador (2000) considera como análise financeira, isto é, do ponto de vista do empreendedor aqui representado pelo pequeno produtor rural.

Young e Fausto (1996) ressaltam que, sob o ponto de vista econômico, os colonos das áreas de fronteira (como outros agentes) buscam maximizar a renda que esperam obter durante o período que permanecerão na terra, e as atividades que compõem a diversidade produtiva devem ser analisadas a partir dos parâmetros julgados pelos autores como fundamentais: o fluxo de caixa descontado de receitas futuras associadas a cada uma das opções de uso e o grau de risco e incerteza envolvido em cada opção.

\section{A Análise de viabilidade financeira}

De acordo com Berger (1980), a aplicação da análise benefício-custo como técnica de administração de empresas rurais é também chamada de análise de rentabilidade privada de investimento. Nesta análise privada apenas os interesses da empresa são considerados e por isso mesmo tomam-se simplesmente as receitas monetárias como benefícios e as despesas como custos.

A diferença entre receitas e custos representa o lucro ou benefício líquido da empresa derivado do projeto em questão (Rêgo, 2003). Assim, para obter a renda líquida da pequena unidade de produção, deve-se considerar a diversidade das atividades familiares na Amazônia. As receitas totais são obtidas a partir dos preços de mercado multiplicados pela quantidade comercializada.

A análise financeira pode ser realizada através do Método de Valor Presente Líquido (VPL) tido por Kassai et al. (2001) como um dos instrumentos sofisticados mais utilizados para se avaliar propostas de investimentos de capital. Seu resultado é obtido pela seguinte fórmula: 


$$
V P L=\sum_{j=0}^{n} R_{t}(1+i)^{-t}-\sum_{j=0}^{n} C_{t}(1+i)^{-t}
$$

Reflete a riqueza em valores monetários do investimento medida pela diferença entre o valor presente das entradas e saídas de caixa, a uma determinada taxa de desconto. Para Resende e Oliveira (2001), o Valor Presente Líquido pode ser definido como a soma algébrica dos valores descontados do fluxo de caixa a ele associado. Estes autores consideram um projeto economicamente viável através do VPL se o fluxo de caixa descontado a uma taxa mínima de atratividade apresentar um resultado maior ou igual a zero e quanto maior o VPL, mais atrativo será o projeto.

Contador (2000), por sua vez, enfatiza a importância deste método para escolha entre projetos alternativos, afirmando que a preferência recai sobre aquele com maior Vpl positivo. Além deste critério, pode-se analisar a taxa de crescimento econômico do projeto através da Taxa Interna de Retorno (TIR), definida pelo mesmo autor como aquela taxa de juros que iguala o valor presente líquido a zero. Logo, é a taxa de desconto que iguala o valor presente dos benefícios de um projeto ao valor presente de seus custos. A fórmula para calcular a TIR é a seguinte:

$$
V P L=\left(\sum_{j=0}^{n} R_{t}(1+i)^{-t}-\sum_{j=0}^{n} C_{t}(1+i)^{-t}\right)=0
$$

Para definir o valor das parcelas, acrescido de juros para amortizar o pagamento de possíveis financiamentos adquiridos junto a terceiros, Kassai (2002) indica o Sistema Francês de Amortização obtido a partir da fórmula abaixo:

$$
A=P\left(\frac{i(1+1)^{n}}{(1+i)^{n}-1}\right)
$$

\section{MATERIAL E MÉTODOS}

\section{Área de estudo}

O estudo abrangeu o Projeto de Assentamento Dirigido Peixoto (PAD Peixoto), localizado entre as coordenadas $9^{\circ} 06^{\prime}$ e $10^{\circ} 30^{\prime}$ de latitude sul e $67^{\circ} 00$ e $67^{\circ} 40^{\prime}$ de longitude oeste de Greenwich, extremo leste do estado do Acre (Figura 1).

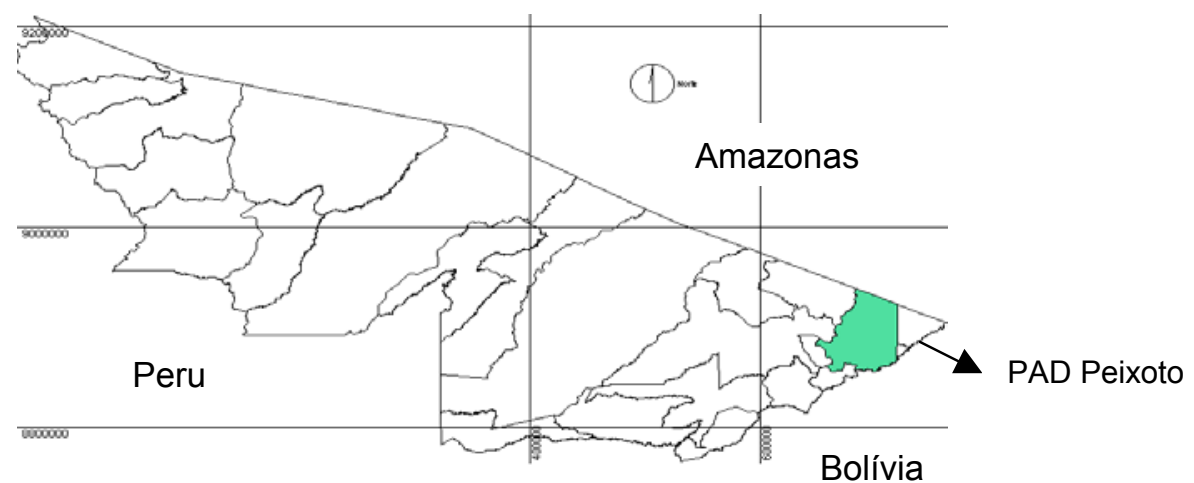

Figura 1. Localização do PAD Peixoto no estado do Acre (Fonte: EMBRAPA, 1999).

Figure 1. Localization of the PAD Peixoto in the Acre State. 


\section{Dados utilizados e fontes}

Os potenciais produtivos da reserva legal foram extraídos dos inventários prospectivos realizados pela EMBRAPA/AC nas propriedades da Associação dos Produtores Rurais em Manejo Florestal e Agricultura (APRUMA) no período compreendido entre 1997 - 2003. Para caracterizar o uso da terra analisaram-se 80 questionários aplicados aleatoriamente em diversas regiões do assentamento entre 1999, 2000 e 2003, extraindo os dados relevantes para caracterizar a produção das famílias, enfocando superfícies/valores de áreas desmatadas e abertas, bem como as frações destinadas aos principais sistemas de produção. Buscando inferir os dados obtidos para as famílias do PAD Peixoto, utilizaram-se os métodos estatísticos de média e moda.

Os dados referentes aos custos e benefícios das atividades produtivas foram coletados através de questionários aplicados junto aos produtores, optando pela média e moda, e em fontes secundárias baseadas em publicações da EMBRAPA (Empresa Brasileira de Pesquisa Agropecuária) - Centro de Pesquisas Agroflorestais do Acre (CPAF/AC). Os preços pagos aos produtores de arroz, feijão, milho, castanha, bezerro, touros, vacas, novilhas, leite, madeira, açaí e copaíba foram obtidos por um levantamento feito na Secretaria de Assistência Técnica e Extensão Rural (SEATER), com comerciantes e com as próprias famílias. Os preços de insumos foram obtidos diretamente no mercado local.

\section{Procedimento metodológico}

Para avaliar a rentabilidade das famílias do PAD Peixoto sob o ponto de vista privado foi utilizada a análise de benefício - custo através do Valor Presente Líquido (VPL), da Taxa Interna de Retorno (TIR) e da renda líquida anual.

As variáveis dividiram-se em custos de investimentos, custos fixos e variáveis, além da mão-deobra (MDO) requerida para as jornadas anuais de trabalho exercido pelas famílias, fator remunerado com um salário mínimo para o homem e outro para a mulher. Quando o conjunto de atividades agrícolas florestais necessitavam de força de trabalho complementar, esta passou a gerar custos variáveis de mãode-obra. As receitas se resumiram aos diversos produtos da unidade de produção (agrícolas e florestais), multiplicados pelos respectivos preços de mercado.

Para descontar os fluxos de caixa utilizaram-se as taxas de juros do Programa Nacional de Agricultura Familiar - PRONAF, sendo a menor de 1,15\% a.a., e maior 4\% a.a..

A análise econômica sob o ponto de vista da sociedade considerou a possibilidade do governo financiar os custos de assentamento e manutenção inicial das famílias. As simulações foram analisadas sob a forma de cenários de desmatamentos, considerando a legislação atual, que prevê a manutenção de $80 \%$ da propriedade sob cobertura florestal e, de acordo com as reivindicações dos produtores, voltar à legislação anterior de 50\%. Foram previstos ainda dois cenários intermediários de $70 \%$ e $60 \%$.

\section{RESULTADOS E DISCUSSÕES}

\section{Análise da renda do cenário $80 \%$ de Reserva Legal}

A floresta do cenário 80\% de reserva legal (RL) gerou uma receita total de R\$ 180,4 mil (receita corrente) o que representou $46,2 \%$ da renda da propriedade.

Ao final de 30 anos as receitas deste cenário totalizaram R\$ 26,7 mil oriundas do leite, significando $6,91 \%$ do total gerado pela propriedade. As comercializações das vacas de descarte somaram $\mathrm{R} \$ 27,5$ mil (7\%), seguidas das vendas de touros $\mathrm{R} \$ 7,3$ mil, representando 1,8\% das receitas totais.

Todo o cenário gerou R\$ 390 mil, com uma predominância de 53,7\% dos produtos obtidos na área de conversão.

Os custos fixos representam 55,3\%, seguido dos custos variáveis (custos operacionais), com 30\% e dos custos de investimentos com 14,46\%. As atividades florestais e agropecuárias seriam realizadas sem a necessidade de contração de MDO de terceiros (MDO variável), já que o valor máximo de trabalho necessário deu-se no ano 4, atingindo 463 diárias.

O fluxo de caixa representado na Figura 2 demonstra que as receitas líquidas negativas permanecem por um longo período que vai desde o ano 0 até o ano 9, indicando que as famílias devem passar por vários anos tendo apenas prejuízos com o empreendimento. 


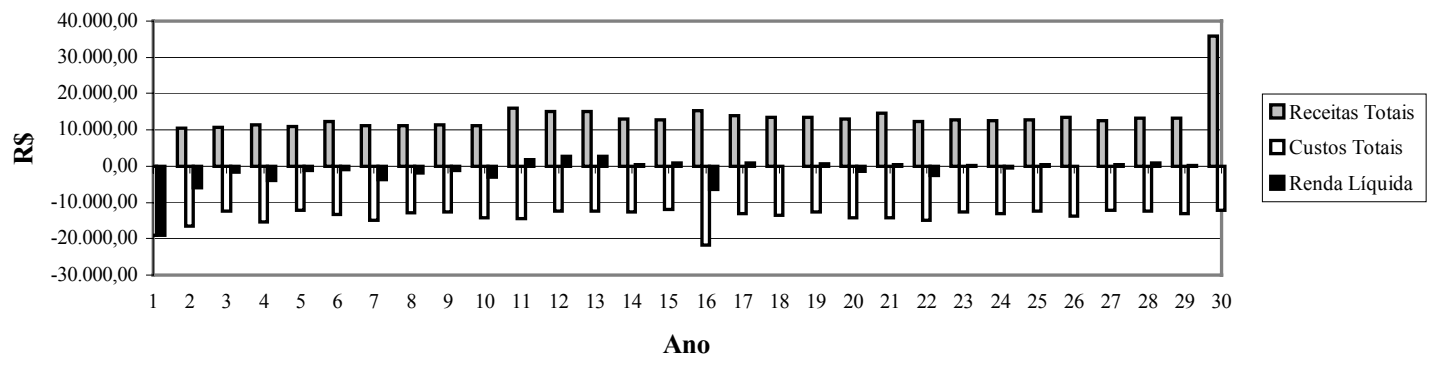

Figura 2. Fluxo de Caixa do Cenário $80 \%$ RL.

Figure 2. Cash Flow of Scenary $80 \%$ LR.

Através da Tabela 1 pode-se notar que as famílias tiveram prejuízos financeiros em todos os critérios de análise, mesmo com todos os potenciais de extração de produtos florestais madeireiros e não madeireiros.

O governo poderia adotar medidas de incentivo através da isenção do ICMS, que tem uma grande importância na composição dos custos variáveis ou disponibilizar técnicos e estrutura para elaborar os planos operativos de manejo florestal. O valor do financiamento totalizou R\$28,7 mil (que nestas condições significaria $\mathrm{R} \$ 387,00 /$ hectare), a serem amortizados a partir do ano 10, dividido em 20 parcelas, com juros de $1,15 \%$ a.a.

Tabela 1. Resultados de Viabilidade Financeira do Cenário 80\% de Reserva Legal.

Table 1. Results of Financial Economic of Scenary 80\% From Legal Reserve.

\begin{tabular}{ccccc}
\hline Cenário & Lucro Líquido & $\mathrm{VPL}_{1,15 \%}$ & $\mathrm{VPL}_{4 \%}$ & $\mathrm{TIR}$ \\
& $\mathrm{R} \$$ & $\mathrm{RS}$ & $\mathrm{R} \$$ & $\%$ \\
\hline $80 \% \mathrm{RL}$ & $-8.855,53$ & $-15.400,53$ & $-23.632,23$ & $-1,09$ \\
\hline
\end{tabular}

\section{Análise da renda do cenário $70 \%$ de Reserva Legal}

Os benefícios da floresta caíram para $\mathrm{R} \$ 159,3$ mil, representando 40,09\%, sendo a madeira ainda a maior geradora dentre os produtos da reserva legal. Os produtos não madeireiros contribuíram com apenas $6 \%$. As receitas da área de conversão aumentaram para R $\$ 238$ mil (60\%).

A diversificação da produção neste cenário gerou uma receita total de R\$ 397,4 mil, o que significa um aumento de aproximadamente $2 \%$ em relação cenário de $80 \%$ de reserva legal. Nota-se através do fluxo de caixa uma pequena elevação na geração de receitas líquidas positivas quando comparadas ao cenário de $80 \%$ RL. No ano 30 são contabilizados todos os valores das benfeitorias (cercas, rebanho total e área de pastagem), o que proporciona um lucro líquido de R\$ 33,3 mil. 


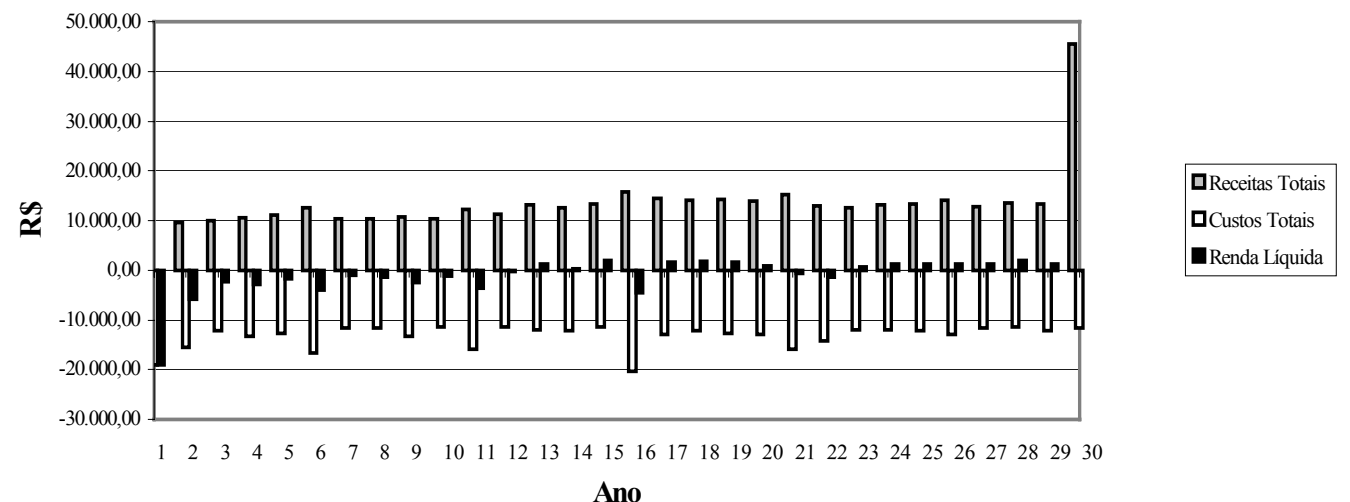

Figura 3. Fluxo de Caixa do Cenário 70\% de Reserva Legal.

Figure 3. Cash Flow of Scenary 70\% Legal Reserve.

A Tabela 2 apresenta os resultados da análise financeira do cenário com $70 \%$ de reserva legal, pois começa a apresentar lucro líquido positivo.

Tabela 2. Resultados da Análise Financeira do Cenário 70\% de Reserva Legal. Table 2. Results of Financial Economic of Scenary $70 \%$ From Legal Reserve.

\begin{tabular}{lcccc}
\hline Cenário & $\begin{array}{c}\text { Lucro Líquido } \\
(\mathrm{R} \$)\end{array}$ & $\begin{array}{c}\mathrm{VPL}_{1,15 \%} \\
(\mathrm{R} \$)\end{array}$ & $\begin{array}{c}\mathrm{VPL}_{4 \%} \\
(\mathrm{R} \$)\end{array}$ & $\begin{array}{c}\text { TIR } \\
(\%)\end{array}$ \\
\hline $70 \% \mathrm{RL}$ & 682,21 & $-16.665,96$ & $-24.877,08$ & 0,06 \\
\hline
\end{tabular}

A TIR nestas condições apresentou-se positiva. Todavia, pelo critério do VPL, o projeto seria inviável às duas taxas de desconto. Além disso, os longos períodos de prejuízos certamente desestimulariam as famílias em permanecer na terra.

\section{Análise da renda do cenário $60 \%$ de Reserva Legal}

A receita gerada na reserva legal reduziu para $\mathrm{R} \$ 133,6$ mil, representando $31,6 \%$ do total geral. A atividade madeireira contribuiu com $\mathrm{R} \$ 111,3$ mil o que representa $26,35 \%$ do total geral e $83 \%$ das receitas oriundas da reserva legal. O segundo produto florestal mais importante foi o açaí, agora com $3,29 \%$ do cenário e 10,4\% da reserva legal. Castanha e copaíba juntos não alcançaram R \$ 6 mil, e representaram $4,2 \%$ das receitas dos produtos florestais.

Em relação ao cenário $70 \%$ RL a receita total da área de conversão aumentou para $\mathrm{R} \$ 288,8$ mil, representando agora $68,38 \%$ dos benefícios da unidade produtiva. Neste cenário o produtor teria disponíveis 18 hectares para implantação da pastagem, cujo limite de formação seria atingido no ano sete.

Os benefícios da reserva legal e área destinada à agricultura e a pecuária aumentaram para $\mathrm{R} \$$ 463,4 mil, ou seja, um aumento de 9,25\% em relação ao cenário de 70\% de reserva legal e 15,92\% em relação ao cenário de $80 \%$.

Os custos totais do cenário $60 \%$ de reserva legal aumentaram para $\mathrm{R} \$ 401$ mil. O aumento é em decorrência da necessidade de uma maior demanda por mão-de-obra e investimentos destinados ao café, agora com 2 hectares, e dos investimentos na construção de cercas (1.800 metros) e formação de pastagem. 
O cenário apresentou uma menor quantidade de fluxos positivos, quando comparado aos cenários anteriores, porém, acontecem em níveis mais elevados.

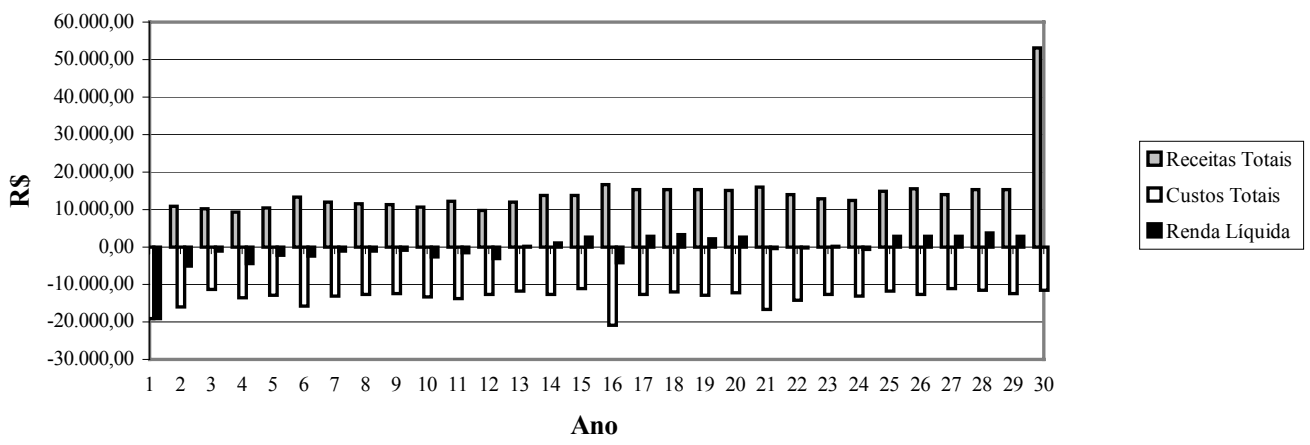

Figura 4. Fluxo de Caixa do Cenário 60\% de Reserva Legal.

Figure 4. Cash Flow of Scenary 60\% Legal Reserve.

Os indicadores de viabilidade financeira da Tabela 3 confirmam o melhor desempenho econômico para o cenário 60\% RL. O lucro líquido de R\$ 21,4 mil encontrado ao final dos 30 anos de investimentos também foi positivo e muito superior ao cenário 70\% RL. Pelo critério da TIR, o empreendimento seria viável, inclusive acima da taxa de juros de $1,15 \%$ aa. Entretanto, seria inviável quando comparada à taxa de $4 \%$ a.a. Pelo critério do VPL à taxa de juros de $4 \%$, o empreendimento seria considerado inviável financeiramente.

Tabela 3. Resultados da Análise Financeira do Cenário 60\% de Reserva Legal.

Table 3. Results of Financial Economic of Scenary 60\% From Legal Reserve.

\begin{tabular}{ccccc} 
Cenário & $\begin{array}{c}\text { Lucro Líquido } \\
\mathrm{R} \$\end{array}$ & $\begin{array}{c}\mathrm{VPL}_{1,15 \%} \\
\mathrm{RS}\end{array}$ & $\begin{array}{c}\mathrm{VPL}_{4 \%} \\
\mathrm{R} \$\end{array}$ & $\begin{array}{c}\mathrm{TIR} \\
\%\end{array}$ \\
\hline $60 \% \mathrm{RL}$ & $21.379,12$ & $5.572,85$ & $-16.521,04$ & 1,67 \\
\hline
\end{tabular}

Com subsídios governamentais os fluxos negativos iniciam-se no ano 10 em função do início dos pagamentos da amortização da dívida e dos custos das demais atividades. Comparado aos cenários $80 \%$ e $70 \%$ RL, apesar de terem que pagar parcelas de valores mais altos, as receitas líquidas a partir do ano 12 são muito superiores.

\section{Análise da renda do cenário $50 \%$ de Reserva Legal}

O potencial máximo de extração de madeira observado entre os agricultores foi de $20 \mathrm{~m}^{3} /$ ano de madeira serrada. Assim, com uma receita anual de R\$3,2 mil, o manejo madeireiro contribuiu com uma receita total de $\mathrm{R} \$ 92,8$ mil de madeira, representando $19,4 \%$ da receita total.

As receitas oriundas da área convertida para a agropecuária totalizaram $\mathrm{R} \$ 365,8$ mil ou 76,48\% da propriedade, quando foram internalizados os benefícios do valor final das benfeitorias de pastagens, cercas e rebanho bovino existente no ano 30.

Os custos variáveis do manejo florestal devido aos gastos com ICMS e frete da madeira apresentaram-se como os menores de todos os cenários estudados. Esta situação acabou compensando a elevação nos custos variáveis e investimentos da pecuária, podendo-se perceber que reduziram no cenário de $50 \%$ RL em quase $60 \%$ em relação ao cenário com maior reserva florestal. As receitas líquidas positivas iniciam-se apenas no ano 16 , porém, permanecem constantes até o final com uma média de R\$ 4 mil/ano, sendo que no ano 30 o benefício total da unidade produtiva aumentou para $\mathrm{R} \$ 80,3$ mil. 


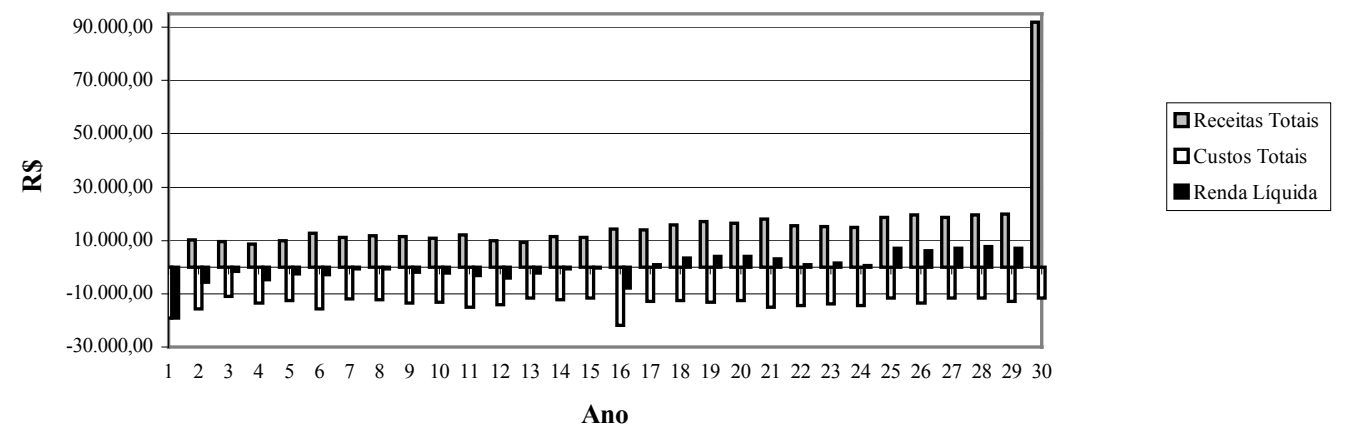

Figura 5. Fluxo de Caixa do Cenário 50\% de Reserva Legal.

Figure 5. Cash Flow of Scenary 50\% Legal Reserve.

Dentre os cenários analisados este é que apresentou o maior lucro líquido ( $\$ 73$ mil). A taxa interna de retorno também se revelou positiva e acima da taxa de juros de $1,15 \%$ (menor taxa de juros do PRONAF), significando que valeria a pena financiar as atividades, pois a unidade produtiva ainda geraria um excedente econômico de R \$ 41 mil, conforme observado na Tabela 4.

Entretanto, à taxa de juros de $4 \%$ o valor presente líquido, a exemplo do cenário anterior, foi negativo (R\$ -2,8 mil), já que a taxa interna de retorno não passou de $3,7 \%$.

Tabela 4. Resultados da Análise Financeira do Cenário 50\% de Reserva Legal.

Table 4. Results of Financial Economic of Scenary 50\% From Legal Reserve.

\begin{tabular}{ccccc}
\hline Cenário & $\begin{array}{c}\text { Lucro Líquido } \\
(\mathrm{R} \$)\end{array}$ & $\begin{array}{c}\mathrm{VPL}_{1,15 \%} \\
(\mathrm{R} \$)\end{array}$ & $\begin{array}{c}\text { VPL } \\
(\mathrm{R} \$)\end{array}$ & $\begin{array}{c}\text { TIR } \\
\%\end{array}$ \\
\hline \multirow{2}{*}{$50 \% \mathrm{RL}$} & \multirow{2}{*}{$73.303,50$} & $41.555,67$ & & $-2.839,75$ \\
& & & 3,72 \\
\hline
\end{tabular}

Buscando atingir este modelo, apesar de seus resultados terem se apresentado com os melhores indicares de viabilidade econômica, as famílias teriam que passar muito anos com fluxos líquidos de caixa negativos (Figura 5, acima). O sistema também necessitaria de subsídios governamentais. Para esta situação, além de isenta-las de contribuição com ICMS e elaboração dos planos de manejo, o governo deve arcar com todos os anos de prejuízos (0 a 10). O total de recursos subsidiados atingiria $\mathrm{R} \$ 45$ mil, sendo cobrados a partir do ano 17 em parcelas fixas de $\mathrm{R} \$ 2,9$ mil, produzindo sensíveis efeitos no fluxo de caixa líquido.

\section{Análise social e sustentabilidade dos pequenos produtores rurais}

Em todos os cenários analisados a rentabilidade privada das famílias é muito baixa. O INCRA responsabiliza-se pela cessão da terra e do crédito para que as famílias possam implementar sua infraestrutura inicial. Atualmente este crédito não ultrapassa R \$ 4.500,00 distribuídos da seguinte forma: R\$ $3.000,00$ para a construção da moradia; $\mathrm{R} \$ 1.500,00$ para alimentação e equipamentos iniciais.

Analisando a Tabela 5 com os possíveis gastos governamentais constata-se que estes recursos são insuficientes para os pequenos produtores iniciarem suas atividades, haja vista o grande período de tempo necessário para o início das receitas líquidas positivas. Nota-se que os gastos tendem a aumentar quando os percentuais das áreas desmatadas são maiores. O cenário com menor parcela de reserva legal possui uma demanda externa de recursos $58 \%$ superiores ao cenário com $80 \%$ de reserva legal, entretanto, 
as receitas obtidas a partir da exploração dos recursos florestais, juntamente com agricultura e pecuária manter-se-iam em níveis mais elevados para aquelas famílias com áreas de conversão maiores.

Tabela 5. Custos dos subsídios governamentais.

Table 5. Costs of the governmental subsidies.

\begin{tabular}{c|c}
\hline CENÁRIO & $\begin{array}{c}\text { CUSTOS DOS SUBSÍDIOS } \\
\text { (R\$ 1.000,00) }\end{array}$ \\
\hline $80 \% \mathrm{RL}$ & 28,7 \\
$70 \% \mathrm{RL}$ & 30,3 \\
$60 \% \mathrm{RL}$ & 38,6 \\
$50 \% \mathrm{RL}$ & 45,1 \\
\hline
\end{tabular}

A proposta social de desenvolvimento rural que mais se aproxima dos pontos levantados nesta seção é aquela apresentada no PROAMBIENTE. Os cálculos apresentados nesta análise podem ser de grande importância para as famílias de produtores rurais e o próprio governo na redução dos custos de oportunidade para a manutenção da reserva legal.

Os números constantes na Tabela 5 comprovam e justificam a necessidade de um empenho maior por parte da sociedade em aumentar os subsídios para uma possível compensação àquelas famílias.

\section{CONCLUSÕES}

Os cenários com áreas maiores de reserva legal, apesar de considerar o máximo da produção de recursos florestais, em condições de livre iniciativa das famílias (métodos tradicionais e predominantes de produção), são economicamente inviáveis sob ponto de vista da análise privada de investimentos.

Em tais condições a floresta realmente funciona como um obstáculo ao desenvolvimento das famílias rurais, já que os cenários que apresentaram os melhores resultados foram aqueles que mantêm $60 \%$ e $50 \%$ de reserva florestal. Portanto a contribuição econômica da atividade florestal não seria suficiente para conter o avanço da pecuária.

Optando por conduzir o empreendimento rural, tendo que imobilizar $80 \%$ de sua propriedade a família não conseguiria cobrir o custo de oportunidade de sua força de trabalho. Isto explica, em parte, o fato das propriedades do PAD Peixoto não possuírem mais esta quantidade de floresta.

Os custos variáveis do manejo florestal madeireiro tiveram expressiva participação na geração de fluxos de caixa negativos em todos os cenários.

A madeira contribuiu com a maior geração de receitas e dentre os produtos florestais nãomadeireiros o que mais influenciou na geração de renda foi o açaí, seguido pela castanha e pela copaíba.

Para manter as famílias sob a restrição imposta pelo Código Florestal Brasileiro a sociedade deve subsidiar todos os recursos de investimentos iniciais e ainda os primeiros anos, quando estão obtendo fluxos de caixa negativos.

\section{REFERÊNCIAS}

ACRE. Zoneamento ecológico e econômico do estado Acre. Vols I, II, III. Rio Branco, 2000.

BRASIL. Medida Provisória no $2.166 / 67$ de 24 de agosto de 2001. Altera os arts. $1^{\circ}, 4^{\circ}, 14^{\circ}, 16^{\circ}$ e $24^{\circ}$, e acresce dispositivos à Lei $\mathrm{n}^{\circ} 4.771$, de 15 de setembro de 1965, que institui o Código Florestal, bem como alter o art. 10 da Lei ${ }^{\circ}$ 9.393, de 19 de dezembro de 1996, que dispõe sobre o Imposto sobre a Propiredade Territorial Rural - ITR, e dá outras providências. Disponível em: http://www.planalto.gov.br./ccivil03/MPV/2166-67.htm.pdf. Acesso em: 20 agosto 2003.

CASAROTTO N. F.; KOPITTKE B. H. Análise de Investimentos. Análise financeira. Engenharia Econômica. Tomada de Decisão. Estratégia Empresarial. 9a ed. São Paulo: Ed. Atlas, 2000.

CONTADOR, C. R. Projetos Sociais - Avaliação e Prática. 4a ed. São Paulo: 2000. 
DALBELlO, L. A relevância do uso do fluxo de caixa como ferramenta de gestão financeira para avaliação da liquidez e capacidade de financiamento de empresas. Florianópolis, 1999. Dissertação (Mestrado) -Universidade Federal de Santa Catarina.

EMPRESA BRASILEIRA DE PESQUISA AGROPECUÁRIA (EMBRAPA). Coeficientes técnicos e avaliação econômica do sistema de produção melhorado da pecuária de leite no Acre. Rio Branco, 2002 (Comunicado Técnico n. 153).

Plano de Manejo Florestal em Regime de Rendimento Sustentado, para 11 lotes do Projeto de Colonização Pedro Peixoto, Ramais Nabor Junior e Granada. Rio Branco. 2000.

Sistemas de Utilização da Terra e seus respectivos Coeficientes Técnicos de Produção no Projeto de Assentamento Dirigido Pedro Peixoto. Rio Branco, 1998.

Tendências da pecuária bovina no Acre entre 1970 e 2000. Rio Branco, 2002.

INSTITUTO NACIONAL DE PESQUISAS ESPACIAIS (INPE). Monitoramento de Floresta Amazônica Brasileira por Satélite: 1998-1999. 22p.

JORNAL O ESTADO. Pecuaristas declaram guerra à MP 2.166. Rio Branco, 25 a 31/1 de 2004. Economia, p. 10-11, 16-17.

Pecuária não trará desenvolvimento ao Acre. Rio Branco, 1 a $7 / 2$ de 2004. Ibama/Meio Ambiente, p. 10-11, 16.

KASSAI, J. R.; KASSAI, S.; SANTOS, A; ASSAF NETO, A. Retorno de Investimento. Abordagem Matemática e Contábil do Lucro Empresarial. São Paulo: Ed. Atlas. 2 ed. 2000.

Relatório do Levantamento Sócio Econômico do Anteprojeto de Criação do Projeto de Desenvolvimento Sustentável do São Salvador. Mâncio Lima, A. C. No prelo.

RÊGO, J. F.; FILHO, O. S. C; BRAGA, R. A. R. Análise econômica dos sistemas de produção familiar rural da região do Vale do Acre - 1996/1997. Universidade Federal do Acre, 2003. 80p.

RÊGO, J. F. Estado e Políticas Públicas - A reocupação econômica da Amazônia durante o regime militar. EDUFMA. São Luís, MA. UFAC, Rio Branco, AC. 2002. 420p.

RESENDE, J. L. P.; OLIVEIRA A. D. Análise econômica e social de projetos florestais. Universidade Federal de Viçosa. Viçosa, 2001. 389 p.

ROCHA, E. Aspectos ecológicos e socioeconômicos do manejo de Euterpe precatoria (açaí) em áreas extrativistas do Acre, Brasil. São Paulo, 2002. Dissertação (Mestrado) - Universidade de São Carlos.

YOUNG, C; FAUSTO J. Valoração dos recursos naturais como instrumento de análise da expansão da fronteira agrícola na Amazônia. In: I ENCONTRO DA SOCIEDADE BRASILEIRA E ECONOMIA ECOLÓGICA, 1996, Campinas. Anais... Águas de Lindóia. 